\title{
Evaluation and Treatment of Seizures and Epilepsy During the COVID-19 Pandemic
}

\author{
Jacob Pellinen ${ }^{1}$ (D) Manisha Gupte Holmes ${ }^{2}$ (D)
}

Accepted: 30 November 2021 / Published online: 26 January 2022

(c) The Author(s), under exclusive licence to Springer Science+Business Media, LLC, part of Springer Nature 2022

\begin{abstract}
Purpose of Review Seizures, including status epilepticus, have been reported in association with acute COVID-19 infection. People with epilepsy (PWE) have suffered from seizure exacerbations during the pandemic. This article reviews the data for clinical and electrographic seizures associated with COVID-19, technical EEG considerations for reducing risk of transmission, and factors contributing to seizure exacerbations in PWE as well as strategies to address this issue.

Recent Findings An increasing number of studies of larger cohorts, accounting for a variety of variables and often utilizing EEG with standardized terminology, are assessing the prevalence of seizures in hospitalized patients with acute COVID-19 infections, and gaining insight into the prevalence of seizures and their effect on outcomes. Additionally, recent studies are evaluating the effect of the pandemic on PWE, barriers faced, and the usefulness of telehealth.

Summary Although there is still much to learn regarding COVID-19, current studies help in assessing the risk of seizures, guiding EEG utilization, and optimizing the use of telehealth during the pandemic.
\end{abstract}

Keywords Convulsions · Clinical neurology $\cdot$ Telemedicine $\cdot$ EEG $\cdot$ Encephalography $\cdot$ Coronavirushis presented the question

\section{Introduction}

COVID-19 presented with a vengeance and uncertainty in early 2020. It is distinguished by its high transmissibility, intense inflammatory response, and hypoxemia. The virus itself produces neurologic manifestations and the virus' consequences of restrictions to healthcare drastically altered how medical care could be delivered in both acute and chronic conditions, seizures, and epilepsy included.

One of the first reports from Wuhan, China, retrospectively looking at 214 patients, reported neurologic manifestations in approximately $36 \%$, specifically CNS symptoms

This article is part of the Topical Collection on Epilepsy

Manisha Gupte Holmes

Manisha.Holmes@nyulangone.org

Jacob Pellinen

Jacob.Pellinen@cuanschutz.edu

1 Department of Neurology, School of Medicine, University of Colorado, Aurora, CO, USA

2 Comprehensive Epilepsy Center, School of Medicine, New York University, New York, NY, USA in $25 \%$, with a greater percentage of CNS manifestations seen in severe infection. Notably, there was impairment of consciousness in $15 \%$ (13/88) of those with severe infection and 2\% (3/126) of those with non-severe infection. The one seizure noted occurred in the severely infected group $[1 \bullet \bullet$. With a known propensity for seizures in inflammatory processes and the critically ill [2], and as evidence of brain imaging abnormalities in COVID-19 grew [3], seizures became an obvious suspect as a contributor to altered mental status. A number of supportive case reports began to arise [4-7]. This presented the question not only of how often are seizures occurring and what role do they play in prognosis but also of how can patients be safely monitored while limiting exposure to EEG technicians?

Apart from new-onset seizures due to acute illness, the impact of COVID-19 on patients with pre-existing epilepsy has been immense. They experienced barriers to obtaining medications, diagnostic studies, and clinic visits, in addition to the isolation and psychological effects suffered by individuals globally. Here, we review the literature from the first year of the COVID-19 pandemic in order to assess the risk of new-onset seizures resulting from COVID-19 infections, the utility of EEG in managing severe COVID-19-related 
illness, the risk of seizure exacerbations in people with epilepsy (PWE), and the pandemic's overall impact on the clinical care of PWE.

\section{Seizures and COVID-19}

The prevalence of seizures in COVID-19 varies in cohorts anywhere from 0 to $26 \%$ with a multitude of case reports $[8,9,10 \bullet, 11]$. Key factors to consider when comparing results are the size and type of cohort, how seizures were determined, how infection with COVID was determined, and if there was pre-existing epilepsy and/or other comorbidities. A systematic review looking specifically at status epilepticus (SE) associated with severe COVID-19 infections found 47 cases reported but $30 \%$ of these did not have EEG performed, and standardized EEG criteria were only used for defining nonconvulsive status epilepticus (NCSE) in 3 cases [12]. Two of the largest studies, each with $>4,000$ COVID-19 patients from Iran and New York, consistently noted seizures in $<1 \%$ of admitted COVID-19 patients $[13 \bullet \bullet, 14]$. A study of 304 patients from the Hubei province in China reported 0 seizures; notably, none had a history of epilepsy [10•]. A study from Chicago, IL, reported $26 \%$ of their cohort had seizures; however, their cohort was defined by COVID-19 positive patients admitted specifically to a neurology unit or had a neurology consult $(n=50)$ [8]. When seizures have been identified in COVID-19 patients, they have not necessarily correlated with disease severity scores or inflammatory markers, but have been associated with a history of epilepsy and brain injury $[15 \bullet \bullet, 16 \bullet \bullet]$. The overall risk of new-onset seizures in the setting of acute COVID-19 infections is low. It is a lower rate of seizures than reported in association with hospitalizations from other coronaviruses such as SARS (2.7\%), MERS (8.6\%), as well as other more common viruses such as influenza A (19.5\%), parainfluenza (12.2\%), or adenovirus (9\%) [17-19].

As with febrile infections in general, COVID-19 may lead to seizure exacerbation in patients with pre-existing epilepsy, and precautions can be taken through the use of antipyretic medications when indicated. The impact of COVID-19 on people with pre-existing epilepsy will be discussed in more detail below.

\section{EEG Findings Associated with COVID-19}

Non-convulsive/subclinical seizures (NCS) and nonconvulsive status epilepticus (NCSE) can contribute to coma and encephalopathy in critically ill patients, and EEG monitoring is an important tool for clinical management [2, 20, 21]. Prior studies in critically ill patients have shown NCS in $8-10 \%$ of patients without brain injury [20], $11 \%$ of patients hospitalized with severe sepsis [21], and 10-13\% of patients admitted with brain injury [21, 22]. NCSE has been noted in $5-8 \%$ of critically ill patients [20, 23]. NCS have been linked to poor outcomes [20,24].

Several studies have reviewed COVID-19 EEG cohorts, with variations in EEG timing and duration, as well as variable additional ancillary testing such as neuroimaging. Despite the variability, some trends have emerged. In a cohort of 197 patients with COVID-19 who underwent continuous EEG (cEEG) monitoring at 9 centers across the USA and Belgium, epileptiform abnormalities of any kind were found in nearly half of patients (48.7\%), electrographic seizures (ES) specifically in 19 (9.6\%), and NCSE in 11 (5.6\%). Of the 19 patients with ES, 14 (73.7\%) had either a history of a CNS disorder (including 6 with history of epilepsy) or intracranial lesions (acute or chronic). Of those without either CNS disorder or intracranial lesion $(n=86)$, 5 patients (5.8\%) had ES. All 5 had acute metabolic risk factors for developing seizures [16••]. These findings are similar, though higher than, two other single center New York cohorts of 111 and 79 COVID-19 patients, and a multicenter study from Michigan with 110 patients that showed any epileptiform abnormality in 35\%, ES in 6-8\%, and NCSE in 2-4\%. Of note, only one of the studies mentioned commented on the number of patients experiencing cardiac arrest, which in itself can be associated with NCS, worse outcomes, and is prevalent in severe COVID-19 infection $[11,25,26]$. There were 11/111 patients who experienced cardiac arrest, and after excluding these patients, the prevalence of any epileptiform abnormality decreased from 35 to $30 \%$, with 1 fewer patient experiencing NCS and NCSE $[15 \bullet \bullet$. There was a higher prevalence of ES when indication for EEG was a clinically apparent seizure-like event or a history of epilepsy and a low prevalence of ES when indication for EEG was persistent altered mental status [15••, 27].

There have also been reports of seemingly novel EEG abnormalities, specifically frontally predominant abnormalities, in patients hospitalized with acute COVID-19 infections [28, 29]. However, based on an overall review of the literature to date, there is no EEG pattern that is specific for patients with neurological manifestations of COVID-19, and a more thorough investigation of these findings with attention to confounding variables is needed to establish correlation [28, 30-32]. Potential confounding variables include body positioning (prone vs supine positioning in ventilated ICU patients), imaging findings, and medical comorbidities.

Association of in-patient mortality and EEG findings has varied, with one study reporting death in 53\% (10/19) of patients with ES compared to 35\% (63/178) without ES, a couple studies reporting no association between any epileptiform finding and in-patient mortality, and one study reporting an association between mortality and need for EEG in the third week of admission $[10 \bullet, 11,15 \bullet \bullet, 33]$. Again, 
there are many factors to consider when interpreting these results, primarily how cohorts were defined. Ultimately, a higher mortality rate in critically ill patients with epileptiform abnormalities is consistent with prior studies and not necessarily unique to COVID-19 [34, 35]. It is expected that higher rates of seizures will be reported in EEG cohorts as indication for EEG inherently biases for those patients who have suspected seizures or seizure risk factors. It is also important to remember most of these studies included patients on sedation and/or anti-seizure medication. It is possible rates of epileptiform abnormalities, especially ES, could be higher without treatment.

Weighing risks and benefits of inpatient EEG monitoring is imperative given COVID-19's unique risk of transmission to patients and healthcare providers, including EEG technologists, particularly as PPE and vaccine availability varies geographically [36••]. Potential ways to minimize risk is to use single-use options and/or reduced montages (compared to the standard 10-20 complement) for screening and long cables allowing for portable machines to be placed outside of patient rooms. This permits technicians and readers to remain outside the room once leads are placed [36••]. Beyond minimizing the risk of transmission, EEG triage may be particularly important in resource-limited settings, as well as during surges in hospital admissions when the number of critically ill patients exceeds EEG monitoring capabilities (Fig. 1).

Overall, the EEG findings most commonly seen in acute COVID-19 infections are not dissimilar to other studies in the critically ill population. Taking the current literature into account, suspicion of NCS/NCSE as a contributor to coma and encephalopathy in COVID-19 infections should be low in the absence of clinically determinable risk factors such as preceding event concerning for seizure, intracranial abnormalities, and CNS disorder-especially epilepsy $[15 \bullet \bullet, 16 \bullet \bullet, 37]$. The overall risk of EEG monitoring in this patient population for the technologists and other healthcare workers will presumably decrease in the post-vaccine era. More studies on this topic will be helpful in addressing EEG triage decisions in hospitals, as well as initiation and duration of treatment with anti-seizure medications.

\section{Epilepsy and COVID-19}

An initial question is whether or not PWE are more susceptible to COVID-19 and have worse outcomes. A large study of hospitalized patients in Iran found of 37,968 COVID-19 patients, $82(0.2 \%)$ had pre-existing epilepsy, with a known $1 \%$ prevalence of epilepsy in Iran. When comparing groups with and without epilepsy, there was no significant difference in the percentage requiring intubation, ICU care, or death. However, PWE were more likely to present with seizure at time of diagnosis $(O R=27)$ [38]. A study of 358 people with an 11\% COVID-19 infection rate comparing PWE, people with psychiatric illness and the general population, found the only factor associated with contraction of COVID-19 was having an affected relative [39].

A number of studies have supported seizure exacerbation during the COVID-19 pandemic, though this is likely multifactorial and not purely related to acute infections [ 40,41 , 42•, 43, 44]. Survey-based studies of patients and providers around the world have associated an increase in seizure frequency during the pandemic to psychological stress, lapses in medication adherence or availability, disrupted sleep cycles, and high baseline seizure frequency [45•, 46, 47].

A major barrier for PWE has been accessed to medication and care. The pandemic has hindered patients from obtaining
Fig. 1 The use of EEG for inpatient management of people with acute COVID-19 infections

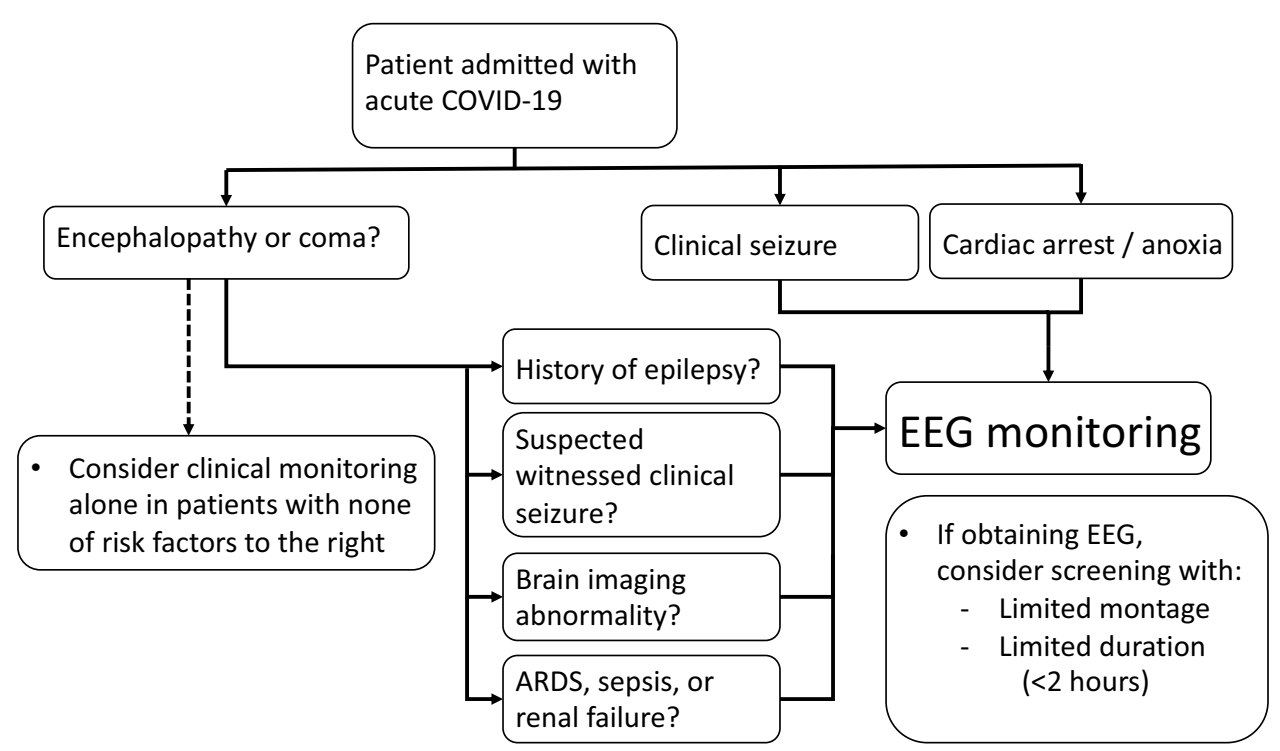


Table 1 Important topics to address during outpatient visits

\begin{tabular}{|c|c|}
\hline Topic & Considerations \\
\hline $\begin{array}{l}\text { [] Medications } \\
\text { - Standing medications } \\
\text { - Rescue medications }\end{array}$ & $\begin{array}{l}\text { - Compliance } \\
\text { - Availability } \\
\text { - Side effects }\end{array}$ \\
\hline [] Seizure frequency & $\begin{array}{l}\text { - Exacerbation factors/triggers } \\
\text { - Seizure related injuries }\end{array}$ \\
\hline [] Comorbid psychiatric illness & $\begin{array}{l}\text { - Depression } \\
\text { - Anxiety } \\
\text { - Other }\end{array}$ \\
\hline [] Comorbid neurologic illness & $\begin{array}{l}\text { - Availability to in-person } \\
\text { examination } \\
\text { - Hesitancy to visit healthcare } \\
\text { facility when needed }\end{array}$ \\
\hline [] Lifestyle & $\begin{array}{l}\text { - Sleep hygiene } \\
\text { - Diet and exercise } \\
\text { - Relationships } \\
\text { - Non-medicinal drug use/abuse }\end{array}$ \\
\hline
\end{tabular}

medications in a variety of ways. It is crucial for healthcare providers and various medical agencies to consider filling prescriptions for longer durations, and automatically by mail order if available, with healthcare providers being alerted if a medication will not be available. In general, healthcare providers should discuss rescue plans with patients, and it is especially imperative during this time. Standard topics assessed during routine outpatient follow-up appointments have become particularly important to re-assess during the pandemic as the landscape of healthcare delivery has changed and factors such as lifestyle changes and access to care have shifted dramatically (Table 1). At the beginning of the pandemic, a consensus statement from epilepsy experts on the treatment approach for PWE was published and serves as a reference for areas that may experience surges

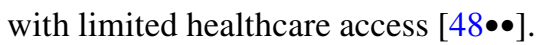

The pandemic caused a rapid shift from in-person care to telehealth. Overall, PWE have expressed satisfaction with telehealth visits with effective management during the pandemic and interest in continued flexibility between in-person and telehealth visits $[49,50 \bullet \bullet]$. The expansion of telehealth is especially helpful in this population that often cannot drive and may require evaluation at a tertiary care center that is not local. Older studies have shown telehealth to be an effective option for some PWE and the pandemic provides the opportunity to broaden availability [51,52].

However, most patients and healthcare providers would agree telehealth works best for established patients and diagnoses. A large study from Germany found that although adherence to anti-seizure medications appeared to be stable in their population with established diagnoses, there was reduced care for people with new-onset epilepsy during the pandemic [53]. Restricted EEG availability, especially in epilepsy monitoring units, during the pandemic forced consideration of alternate methods of diagnoses. A recent publication found that outpatient smartphone video recordings of clinical events are highly reliable in predicting epileptic seizures when reviewed by an epilepsy expert, with a specificity of $93.3 \%$ [54]. Smartphone devices are now widely available and likely in close proximity of witnesses. A series during the pandemic demonstrated childhood absence could be effectively diagnosed and ultimately treated despite lack of immediate access to EEG by performing hyperventilation over telehealth [55].

PWE now have increasing availability of COVID-19 vaccination. At this time, there is no evidence PWE are at higher risk of side effects following vaccination. As fever can lower the seizure threshold and the vaccine could provoke a fever, PWE prone to seizures in the setting of febrile illness can consider taking acetaminophen the day of and following vaccination as an antipyretic. Vaccination is also largely recommended for those who may be on immunomodulatory therapy for their epilepsy after discussion with their provider [56].

\section{Conclusions}

New-onset seizures in acute COVID-19 infection are rare. The risk of seizures is the highest in those who experience a witnessed seizure-like event and those who have pre-existing epilepsy or brain injury. Encephalopathy can be common following severe COVID-19 illness requiring prolonged sedation. However, EEG studies have found a low prevalence of NCS or NCSE in the absence of risk factors (though confounded by treatment with ASM and sedation), and no EEG signature for COVID-19 has been demonstrated consistently. If EEG resources are limited, patients should be treated clinically and those with risk factors for seizures should be given priority for EEG. Limited montage singleuse EEG leads can be helpful for screening. It is important to remember many studies were conducted at the beginning of the pandemic in acutely hospitalized patients with moderate to severe disease; there is no data yet on development of epilepsy with chronic COVID-19 symptoms.

While PWE do not have an increased risk of COVID-19 infection, they are a vulnerable population in terms of risk for seizure exacerbation due to the many complications presented by the pandemic. Healthcare providers need to help patients as best they can to optimize medication adherence, rescue plans, and access to care. Technology has been a tremendous asset and should be leveraged to provide flexibility going forward. COVID-19 vaccination should be encouraged in PWE as there is no evidence of increased side effects in this population at this time. 
Author Contribution Jacob Pellinen and Manisha Holmes contributed equally to this manuscript.

\section{Compliance with Ethical Standards}

Ethics Approval Not applicable.

Consent to Participate Not applicable.

Consent for Publication Not applicable.

Competing Interests Jacob Pellinen has no conflicts of interest to disclose. Manisha G. Holmes has no conflicts of interest to disclose.

\section{References}

Papers of particular interest, published recently, have been highlighted as:

- Of importance

$\bullet$ Of major importance

1.•• Mao L, Jin H, Wang M, Hu Y, Chen S, He Q, et al. Neurologic manifestations of hospitalized patients with coronavirus disease 2019 in Wuhan, China. JAMA Neurol. 2020. This study of 214 patients was the first to report on neurologic manifestations of COVID-19.

2. Osman G, Friedman D, Hirsch LJ. Diagnosing and monitoring seizures in the ICU: the role of continuous eeg for detection and management of seizures in critically ill patients, including the ictal-interictal continuum. Curr Clin Neurol. 2017.

3. Katal S, Balakrishnan S, Gholamrezanezhad A. Neuroimaging and neurologic findings in COVID-19 and other coronavirus infections: a systematic review in 116 patients [Internet]. J. Neuroradiol. Elsevier Masson s.r.l.; 2021 [cited 2021 Apr 25]. p. 43-50. Available from: https://pubmed.ncbi.nlm.nih.gov/32603 $770 /$

4. Sohal S, Mansur M. COVID-19 Presenting with Seizures. IDCases. 2020;

5. Vollono C, Rollo E, Romozzi M, Frisullo G, Servidei S, Borghetti A, et al. Focal status epilepticus as unique clinical feature of COVID-19: a case report. Seizure. 2020;

6. Balloy G, Leclair-Visonneau L, Péréon Y, Magot A, Peyre A, Mahé PJ, et al. Non-lesional status epilepticus in a patient with coronavirus disease 2019 [Internet]. Clin. Neurophysiol. Elsevier Ireland Ltd; 2020 [cited 2021 Apr 25]. p. 2059-61. Available from: /pmc/articles/PMC7217773/

7. Farhadian S, Farhadian S, Glick LR, Vogels CBF, Thomas J, Chiarella J, et al. Acute encephalopathy with elevated CSF inflammatory markers as the initial presentation of COVID-19. BMC Neurol [Internet]. BioMed Central Ltd.; 2020 [cited 2021 Apr 25];20. Available from: https://covid19.elsevierpure.com/ en/publications/acute-encephalopathy-with-elevated-csf-infla mmatory-markers-as-th

8. Pinna P, Grewal P, Hall JP, Tavarez T, Dafer RM, Garg R, et al. Neurological manifestations and COVID-19: Experiences from a tertiary care center at the Frontline. J Neurol Sci [Internet]. Elsevier B.V.; 2020 [cited 2021 Apr 25];415. Available from: https://pubmed.ncbi.nlm.nih.gov/32570113/

9. Asadi-Pooya AA, Simani L, Shahisavandi M, Barzegar Z. COVID-19, de novo seizures, and epilepsy: a systematic review [Internet]. Neurol. Sci. Springer-Verlag Italia s.r.1.; 2021 [cited
2021 Apr 25]. p. 415-31. Available from: https://doi.org/10. 1007/s10072-020-04932-2

10. Lu L, Xiong W, Liu D, Liu J, Yang D, Li N, et al. New-onset acute symptomatic seizure and risk factors in Corona Virus Disease 2019: a retrospective multicenter study. Epilepsia. 2020. This study is a multicenter study from Hubei, China, reporting on the prevalance of acute symptomatic seizures in 304 admitted COVID-19 patients.

11. Danoun OA, Zillgitt A, Hill C, Zutshi D, Harris D, Osman G, et al. Outcomes of seizures, status epilepticus, and EEG findings in critically ill patient with COVID-19. Epilepsy Behav [Internet]. Academic Press Inc.; 2021 [cited 2021 Apr 25];118. Available from: https://pubmed.ncbi.nlm.nih.gov/33770609/

12. Dono F, Nucera B, Lanzone J, Evangelista G, Rinaldi F, Speranza R, et al. Status epilepticus and COVID-19: a systematic review [Internet]. Epilepsy Behav. Academic Press Inc.; 2021 [cited 2021 Apr 25]. Available from: https://pubmed.ncbi.nlm. nih.gov/33743344/

13.• Frontera JA, Sabadia S, Lalchan R, Fang T, Flusty B, Millar-Vernetti $\mathrm{P}$, et al. A prospective study of neurologic disorders in hospitalized patients with COVID-19 in New York City. Neurology [Internet]. NLM (Medline); 2021 [cited 2021 Apr 25];96:e57586. Available from: https://covid19.elsevierpure.com/fi/publi cations/a-prospective-study-of-neurologic-disorders-in-hospi talized-patie. This study is a prospective, multicenter study from New York City that assessed the prevalance of new neurologic disorders in 4,491 adult patients admitted with COVID-19. Infected patients with and without new neurologic disorders were compared to determine if there were differences in comorbities, treatment, and discharge disposition.

14. Keshavarzi A, Janbabaei G, Kheyrati L, Ghavamabad LH, AsadiPooya AA. Seizure is a rare presenting manifestation of COVID19. Seizure [Internet]. W.B. Saunders Ltd; 2021 [cited 2021 Apr 25];86:16-8. Available from: https://pubmed.ncbi.nlm.nih.gov/ 33515905/

15.•• Pellinen J, Carroll E, Friedman D, Boffa M, Dugan P, Friedman DE, et al. Continuous EEG findings in patients with COVID-19 infection admitted to a New York academic hospital system. Epilepsia. 2020. This study of 111 patients with COVID-19 and EEG assessed if there was an association between ACNS standardized EEG findings and disease severity, inflammaroty markers, brain imaging abnormalities, or comorbid conditions. Patients suffering cardiac arrest were analyzed separately.

16.• Lin L, Al-Faraj A, Ayub N, Bravo P, Das S, Ferlini L, et al. Electroencephalographic abnormalities are common in COVID-19 and are associated with outcomes. Ann Neurol [Internet]. John Wiley and Sons Inc; 2021 [cited 2021 Apr 25];89. Available from: https://pubmed.ncbi.nlm.nih.gov/33704826/. This multicenter study of 197 patients from the USA and Belgium with COVID-19 and EEG assessed if there was an association between ACNS standardized EEG findings and in hospital mortality or length of stay. Systemic complications, intracranial lesions, history of CNS disorders, and their relation to EEG findings were also assessed.

17. Li Y, Li H, Fan R, Wen B, Zhang J, Cao X, et al. Coronavirus infections in the central nervous system and respiratory tract show distinct features in hospitalized children. Intervirology [Internet]. S. Karger AG; 2017 [cited 2021 Mar 8];59:163-9. Available from: https://pubmed.ncbi.nlm.nih.gov/28103598/

18. Saad M, Omrani AS, Baig K, Bahloul A, Elzein F, Matin MA, et al. Clinical aspects and outcomes of 70 patients with Middle East respiratory syndrome coronavirus infection: a single-center experience in Saudi Arabia. Int J Infect Dis [Internet]. Elsevier; 2014 [cited 2021 Mar 8];29:301-6. Available from: https://pubmed.ncbi.nlm.nih.gov/25303830/ 
19. Chiu SS, Tse CY, Lau YL, Peiris M. Influenza A infection is an important cause of febrile seizures. Pediatrics [Internet]. Pediatrics; 2001 [cited 2021 Mar 8];108. Available from: https:// pubmed.ncbi.nlm.nih.gov/11581471/

20. Oddo M, Carrera E, Claassen J, Mayer SA, Hirsch LJ. Continuous electroencephalography in the medical intensive care unit. Crit Care Med. 2009;

21. Gilmore EJ, Gaspard N, Choi HA, Cohen E, Burkart KM, Chong $\mathrm{DH}$, et al. Acute brain failure in severe sepsis: a prospective study in the medical intensive care unit utilizing continuous EEG monitoring. Intensive Care Med. 2015;

22. Limotai C, Ingsathit A, Thadanipon K, McEvoy M, Attia J, Thakkinstian A. How and whom to monitor for seizures in an ICU: a systematic review and meta-analysis. Crit Care Med. 2019;

23. Benbadis SR, Tatum IV WO. Prevalence of nonconvulsive status epilepticus in comatose patients [5] [Internet]. Neurology. Lippincott Williams and Wilkins; 2000 [cited 2021 Apr 25]. p. 1421-3. Available from: https://pubmed.ncbi.nlm.nih.gov/11087 $805 /$

24. Kurtz P, Gaspard N, Wahl AS, Bauer RM, Hirsch LJ, Wunsch H, et al. Continuous electroencephalography in a surgical intensive care unit. Intensive Care Med [Internet]. Intensive Care Med; 2014 [cited 2021 Apr 29];40:228-34. Available from: https:// pubmed.ncbi.nlm.nih.gov/24240843/

25. Knight WA, Hart KW, Adeoye OM, Bonomo JB, Keegan SP, Ficker DM, et al. The incidence of seizures in patients undergoing therapeutic hypothermia after resuscitation from cardiac arrest. Epilepsy Res [Internet]. NIH Public Access; 2013 [cited 2021 Apr 29];106:396-402. Available from: /pmc/articles/ PMC3961478/

26. Miles JA, Mejia M, Rios S, Sokol SI, Langston M, Hahn S, et al. Characteristics and outcomes of in-hospital cardiac arrest events during the COVID-19 pandemic: a single-center experience from a New York city public hospital. Circ Cardiovasc Qual Outcomes [Internet]. Lippincott Williams and Wilkins; 2020 [cited 2021 Apr 29];13:825-31. Available from: https:// pubmed.ncbi.nlm.nih.gov/32975134/

27. Waters BL, Michalak AJ, Brigham D, Thakur KT, Boehme A, Claassen J, et al. Incidence of electrographic seizures in patients with COVID-19. Front Neurol [Internet]. Frontiers Media S.A.; 2021 [cited 2021 Apr 25];12. Available from: https://pubmed. ncbi.nlm.nih.gov/33613431/

28. Galanopoulou AS, Ferastraoaru V, Correa DJ, Cherian K, Duberstein S, Gursky J, et al. EEG findings in acutely ill patients investigated for SARS-CoV-2/COVID-19: A small case series preliminary report. Epilepsia Open [Internet]. Wiley-Blackwell Publishing Ltd; 2020 [cited 2021 Apr 19];5:314-24. Available from: https://pubmed.ncbi.nlm.nih.gov/32537529/

29. Le Guennec L, Devianne J, Jalin L, Cao A, Galanaud D, Navarro $\mathrm{V}$, et al. Orbitofrontal involvement in a neuroCOVID-19 patient. Epilepsia [Internet]. Blackwell Publishing Inc.; 2020 [cited 2021 Apr 29];61:e90-4. Available from:/pmc/articles/ PMC7361605/?report=abstract

30. Vellieux G, Sonneville R, Vledouts S, Jaquet P, Rouvel-Tallec A, d'Ortho MP. COVID-19-associated neurological manifestations: an emerging electroencephalographic literature [Internet]. Front. Physiol. Frontiers Media S.A.; 2021 [cited 2021 Apr 19]. Available from: /pmc/articles/PMC7933549/

31. Antony AR, Haneef Z. Systematic review of EEG findings in 617 patients diagnosed with COVID-19 [Internet]. Seizure. W.B. Saunders Ltd; 2020 [cited 2021 Apr 19]. p. 234-41. Available from: https://pubmed.ncbi.nlm.nih.gov/33121875/

32. Vespignani H, Colas D, Lavin BS, Soufflet C, Maillard L, Pourcher V, et al. Report of EEG Finding on Critically Ill Patients with COVID -19. Ann Neurol. 2020;
33. Skorin I, Carrillo R, Perez CP, Sanchez N, Parra J, Troncoso P, et al. EEG findings and clinical prognostic factors associated with mortality in a prospective cohort of inpatients with COVID19. Seizure [Internet]. W.B. Saunders Ltd; 2020 [cited 2021 Mar 16];83:1-4. Available from: https://pubmed.ncbi.nlm.nih.gov/ 33075670/

34. Abend NS, Arndt DH, Carpenter JL, Chapman KE, Cornett KM, Gallentine WB, et al. Electrographic seizures in pediatric ICU patients: cohort study of risk factors and mortality. Neurology [Internet]. 2013 [cited 2021 Apr 27];81:383-91. Available from: https://www.ncbi.nlm.nih.gov/pmc/articles/pmid/23794680/? tool=EBI

35. Tabaeizadeh M, Aboul Nour H, Shoukat M, Sun H, Jin J, Javed F, et al. Burden of epileptiform activity predicts discharge neurologic outcomes in severe acute ischemic stroke. Neurocrit Care Springer. 2020;32:697-706.

36.• Gelisse P, Rossetti AO, Genton P, Crespel A, Kaplan PW. How to carry out and interpret EEG recordings in COVID-19 patients in ICU? Clin. Neurophysiol. 2020. This review highlights technical considerations and safety of EEG monitoring in COVID-19 patients and common ICU EEG artifact.

37. Kubota T, Gajera PK, Kuroda N. Meta-analysis of EEG findings in patients with COVID-19 [Internet]. Epilepsy Behav. Academic Press Inc.; 2021 [cited 2021 Mar 10]. Available from: https://pubmed.ncbi.nlm.nih.gov/33342709/

38. Asadi-Pooya AA, Emami A, Akbari A, Javanmardi F. COVID-19 presentations and outcome in patients with epilepsy. Acta Neurol Scand [Internet]. Blackwell Publishing Ltd; 2021 [cited 2021 May 26];143:624-8. Available from: https://pubmed.ncbi.nlm. nih.gov/33590880/

39. Asadi-Pooya AA, Shahisavandi M, Sadeghian S, Nezafat A, Nabavizadeh SA, Barzegar Z. Is the risk of COVID-19 contraction increased in patients with epilepsy? Epilepsy Behav [Internet]. Academic Press Inc.; 2021 [cited 2021 Apr 27];115. Available from: https://pubmed.ncbi.nlm.nih.gov/ $33450616 /$

40. Miller WR, Von Gaudecker J, Tanner A, Buelow JM. Epilepsy self-management during a pandemic: experiences of people with epilepsy. Epilepsy Behav [Internet]. Academic Press Inc.; 2020 [cited 2021 Mar 8];111:107238. Available from: /pmc/articles/ PMC7316066/

41. Alkhotani A, Siddiqui MI, Almuntashri F, Baothman R. The effect of COVID-19 pandemic on seizure control and selfreported stress on patient with epilepsy. Epilepsy Behav [Internet]. Academic Press Inc.; 2020 [cited 2021 Mar 8];112:107323. Available from: /pmc/articles/PMC7359799/

42. Assenza G, Lanzone J, Brigo F, Coppola A, Di Gennaro G, Di Lazzaro V, et al. Epilepsy care in the time of COVID-19 pandemic in Italy: risk factors for seizure worsening. Front Neurol [Internet]. Frontiers Media S.A.; 2020 [cited $2021 \mathrm{Mar}$ 8];11:737. Available from: https://www.frontiersin.org/artic le/10.3389/fneur.2020.00737/full. This study surveyed $\mathbf{4 5 6}$ PWE and 472 people without epilepsy during the COVID19 lockdown in Italy in spring of 2020 and asessed seizure freuqency, mood, and sleep. Groups were compared and risk facotrs for increased seizures were presented.

43. Huang S, Wu C, Jia Y, Li G, Zhu Z, Lu K, et al. COVID-19 outbreak: the impact of stress on seizures in patients with epilepsy. Epilepsia [Internet]. Blackwell Publishing Inc.; 2020 [cited 2021 Mar 8];61:1884-93. Available from:/pmc/articles/ PMC7436883/

44. Fonseca E, Quintana M, Lallana S, Luis Restrepo J, Abraira L, Santamarina E, et al. Epilepsy in time of COVID-19: a surveybased study. Acta Neurol Scand [Internet]. Blackwell Publishing Ltd; 2020 [cited 2021 Mar 8];142:545-54. Available from: /pmc/ articles/PMC7460986/?report=abstract 
45.• Thorpe J, Ashby S, Hallab A, Ding D, Andraus M, Dugan P, et al. Evaluating risk to people with epilepsy during the COVID19 pandemic: preliminary findings from the COV-E study. Epilepsy Behav [Internet]. 2021 [cited 2021 Mar 10];115:107658. Available from: https://doi.org/10.1016/j.yebeh.2020.107658. This is a survey-based study with preliminary results from of 463 PWE and their caregivers in the UK asessing the heatlh and wellbeing of PWE during the COVID-19 pandemic.

46. Zeng C, Meng H, Zhu Y, Yao L, Lian Y, Zhu Y, et al. Correlation of seizure increase and COVID-19 outbreak in adult patients with epilepsy: findings and suggestions from a nationwide multicentre survey in China. Seizure [Internet]. W.B. Saunders Ltd; 2021 [cited 2021 Apr 27];88:102-8. Available from: https:// pubmed.ncbi.nlm.nih.gov/33839561/

47. Rosengard JL, Donato J, Ferastraoaru V, Zhao D, Molinero I, Boro A, et al. Seizure control, stress, and access to care during the COVID-19 pandemic in New York City: The patient perspective. Epilepsia [Internet]. Blackwell Publishing Inc.; 2021 [cited 2021 Apr 27];62:41-50. Available from:/pmc/articles/ PMC7753328/

48.• French JA, Brodie MJ, Caraballo R, Devinsky O, Ding D, Jehi L, et al. Keeping people with epilepsy safe during the COVID-19 pandemic. Neurology [Internet]. NLM (Medline); 2020 [cited 2021 Mar 10]. p. 1032-7. Available from: https://pubmed.ncbi. nlm.nih.gov/32327490/. Consensus recommendations from global epilepsy experts regarding treatment of epilepsy patients during the COVID-19 pandemic particularly during hosital surges and lockdowns.

49. von Wrede R, Moskau-Hartmann S, Baumgartner T, Helmstaedter C, Surges R. Counseling of people with epilepsy via telemedicine: experiences at a German tertiary epilepsy center during the COVID-19 pandemic. Epilepsy Behav [Internet]. Academic Press Inc.; 2020 [cited 2021 Apr 27];112:107298. Available from: /pmc/articles/PMC7422810/

50.• Datta P, Barrett W, Bentzinger M, Jasinski T, Jayagopal LA, Mahoney A, et al. Ambulatory care for epilepsy via telemedicine during the COVID-19 pandemic. Epilepsy Behav [Internet]. Academic Press Inc.; 2021 [cited 2021 Apr 27];116. Available from: https://pubmed.ncbi.nlm.nih.gov/33545652/. This study assessed telehealth effectiveness and patient satistication among 223 visits at a level 4 epilepsy center in the spring of 2020.
51. Rasmusson KA, Hartshorn JC. A comparison of epilepsy patients in a traditional ambulatory clinic and a telemedicine clinic. Epilepsia [Internet]. Epilepsia; 2005 [cited 2021 Apr 27];46:767-70. Available from: https://pubmed.ncbi.nlm.nih. gov/15857445/

52. Bahrani K, Singh MB, Bhatia R, Prasad K, Vibha D, Shukla G, et al. Telephonic review for outpatients with epilepsy-a prospective randomized, parallel group study. Seizure [Internet]. W.B. Saunders Ltd; 2017 [cited 2021 Apr 27];53:55-61. Available from: https://pubmed.ncbi.nlm.nih.gov/29127858/

53. Mueller TM, Kostev K, Gollwitzer S, Lang JD, Stritzelberger $\mathrm{J}$, Westermayer V, et al. The impact of the coronavirus disease (COVID-19) pandemic on outpatient epilepsy care: an analysis of physician practices in Germany. Epilepsy Behav [Internet]. Epilepsy Behav; 2021 [cited 2021 Mar 16];117:107833. Available from: http://www.ncbi.nlm.nih.gov/pubmed/33618316

54. Tatum WO, Hirsch LJ, Gelfand MA, Acton EK, Lafrance WC, Duckrow RB, et al. Assessment of the predictive value of outpatient smartphone videos for diagnosis of epileptic seizures [Internet]. JAMA Neurol. American Medical Association; 2020 [cited 2021 Apr 19]. p. 593-600. Available from: https://pubmed.ncbi.nlm.nih.gov/31961382/

55. Stafstrom CE, Sun LR, Kossoff EH, Dabrowski AK, Singhi S, Kelley SA. Diagnosing and managing childhood absence epilepsy by telemedicine. Epilepsy Behav [Internet]. Academic Press Inc.; 2020 [cited 2021 Mar 16];115. Available from: https://pubmed.ncbi.nlm.nih.gov/33323339/

56. COVID-19 vaccines and people with epilepsy // International League Against Epilepsy [Internet]. [cited 2021 Apr 27]. Available from: https://www.ilae.org/patient-care/covid-19-and-epile psy/covid-19-vaccines-and-people-with-epilepsy

Publisher's Note Springer Nature remains neutral with regard to jurisdictional claims in published maps and institutional affiliations. 